\title{
FORWAND BACKWARD ELECTRON YIELD RATIO FOR $\alpha$-PARTICLE INDUCED EMISSION FROM DIFFERENT MATERIALS
}

\author{
V.P. Zhurenko', S.I. Kononenko ${ }^{1}$, O.V. Kalantaryan ${ }^{1}$, S.S. Avotin' ${ }^{2}$, N.Ya. Rokhmanov ${ }^{2}$ \\ ${ }^{I}$ V.N. Karazin Kharkiv National University, Kharkiv, Ukraine; \\ ${ }^{2}$ Kharkiv National Agrarian University, «Dokuchaieske-2», Kharkiv region, Ukraine \\ E-mail:v.zhurenko@gmail.com
}

In this work, the ratio of forward and backward electron yields for emission induced by the isotropic flux of $\alpha$ particles from zinc was measured. On the basis of the measured values and experimental data obtained in earlier experiments for other materials, a systematization of the electron yield ratio for forward and backward emission was done, and a relationship of the ratio with stopping power of an ion in a substance was found. The dependence of work function for various materials on the ratio of the electron emission yields was analyzed.

PACS: 79.20.Rf78

\section{INTRODUCTION}

Energy losses of a fast ion in matter can be anisotropic, that is associated with the dominant transfer of energy to electrons, which, as a result of collisions, move in the direction of the primary incident particle. Experimentally, this phenomenon can be observed in the study of secondary electron emission induced by a flux of fast ions from the front (from the side of incidence of the beam - backward emission) and rear (from the side of the beam exit - forward emission) surfaces of a thin target. The emission research of Mekback, Brownstein and Arista [1] was the pioneering work in which attention was drawn to this phenomenon. Since then, considerable attention has been paid to the study of the difference between the electron yields for the forward emission $\gamma_{F}$ and for the backward one $\gamma_{B}$, namely, the ratio $R=\gamma_{F} / \gamma_{B}$ depending on various parameters [2-8]. The difference can be explained by the fact that an electron yield of emission is directly proportional to the stopping power of the ion in the substance $[9,10]$. In turn, it allows, by studying the behavior of the R-ratio or R-factor of Mekback, to obtain information about the energy loss of a moving ion in a substance and the distribution of this energy among various groups of electrons [8].

Emission process occurs due to the collisions of the ion with the atoms of the target material and the formation of electrons of different velocities. Slow electrons, produced both by direct collisions with small transferred momenta, and by ionization of atoms by the wake potential, move isotropically in matter, while fast convoy and $\delta$-electrons move mainly in the direction of ion motion [11]. Since a significant part of the energy of a fast ion is transferred to electrons moving in the direction of motion of the primary particle (convoy and $\delta$-electrons), a difference arises in the energy losses of the particle in the forward and backward directions.

In our earlier works, we experimentally investigated the ratio $\mathrm{R}$ for a number of metals and assumed the existence of a certain dependence of this parameter on the stopping power of an ion in a substance [12]. In this work, we measured the ratio $\mathrm{R}$ for zinc in the case of emission induced by an isotropic flux of fast $\alpha$-particles, investigated the correlation between the work function of electrons and the ratio $\mathrm{R}$, and also systematized the data on the dependence of $\mathrm{R}$ on the stopping power of an ion in the substance.

\section{EXPERIMENTAL SETUP}

Forward-backward asymmetry experiment for zinc was done on the experimental setup described in detail in [13]. The projectile source (Fig. 1) was radioisotope with isotope $\mathrm{Pu}^{239}$ (initial flow intensity 4.64·10 particles per second, energy of $\alpha$-particles is $5.15 \mathrm{MeV}$, isotropic flux of projectile radiated into the solid angle $2 \pi$ ). $\alpha$-particles passed through the thin aluminum foil target (thickness $5.6 \mu \mathrm{m}$ ) induced forward emission from deposited zinc layer and backward emission from the surface of massive zinc collector. Electron yields of forward $\gamma_{\mathrm{F}}$ and backward $\gamma_{\mathrm{B}}$ emissions were calculated basing on electrometric current measurement. The experiment was performed at room temperature and standard vacuum conditions with residual gas pressure approximately $2 \cdot 10^{-4} \mathrm{~Pa}$.

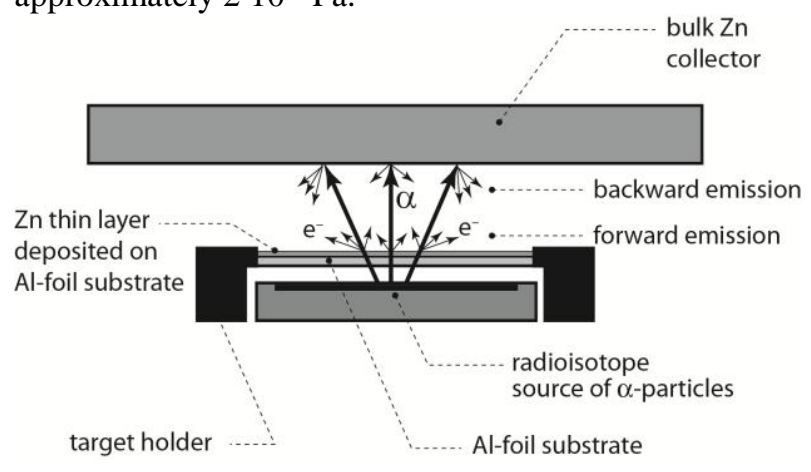

Fig. 1. Scheme of forward-backward electron emission experiments

The target was aluminum foil substrate with deposited zinc layer (thickness of $0.85 \mu \mathrm{m}$ ). Zinc layer on the substrate surface was formed by thermal vacuum deposition of pure $\mathrm{Zn}(99.99 \%)$ in vacuum universal station «VUP-5M». The residual gas pressure was approximately $2 \cdot 10^{-3} \mathrm{~Pa}$. 


\section{SRIM SIMULATIONS}

We simulated passage of fast alpha-particles through the target in SRIM/TRIM software [14]. Two cases were described: normal incidence and passage at angle of $20^{\circ}$. Initially, an isotropic particle flux falls on the target. As a result of oblique incidence at different angles, some of the particles stop in the target, since for these particles the path length can become equal to the path length of the ion in the substance. As a result, at the exit from the target, the particles have an energy distribution from 0 to $\mathrm{E}_{\max }$, which corresponds to normally incident ions, and is equal to $3.91 \mathrm{MeV}$ in our case (calculated by SRIM/TRIM). The energy of ions impinged at $20^{\circ}$ is approximately $3.82 \mathrm{MeV}$ after the passage of the target.

Figs. 2, 3 shows the calculation of the passage of ions with energy of $5.15 \mathrm{MeV}$ for normal and oblique incidence. The ions transmitted through the target with some scattering, only a small fraction of ions are backscattered. Energy losses were evaluated by TRIM's «Ion stopping and range tables». Electron stopping power is the main part of the total energy loss of the projectiles in the zinc layer.

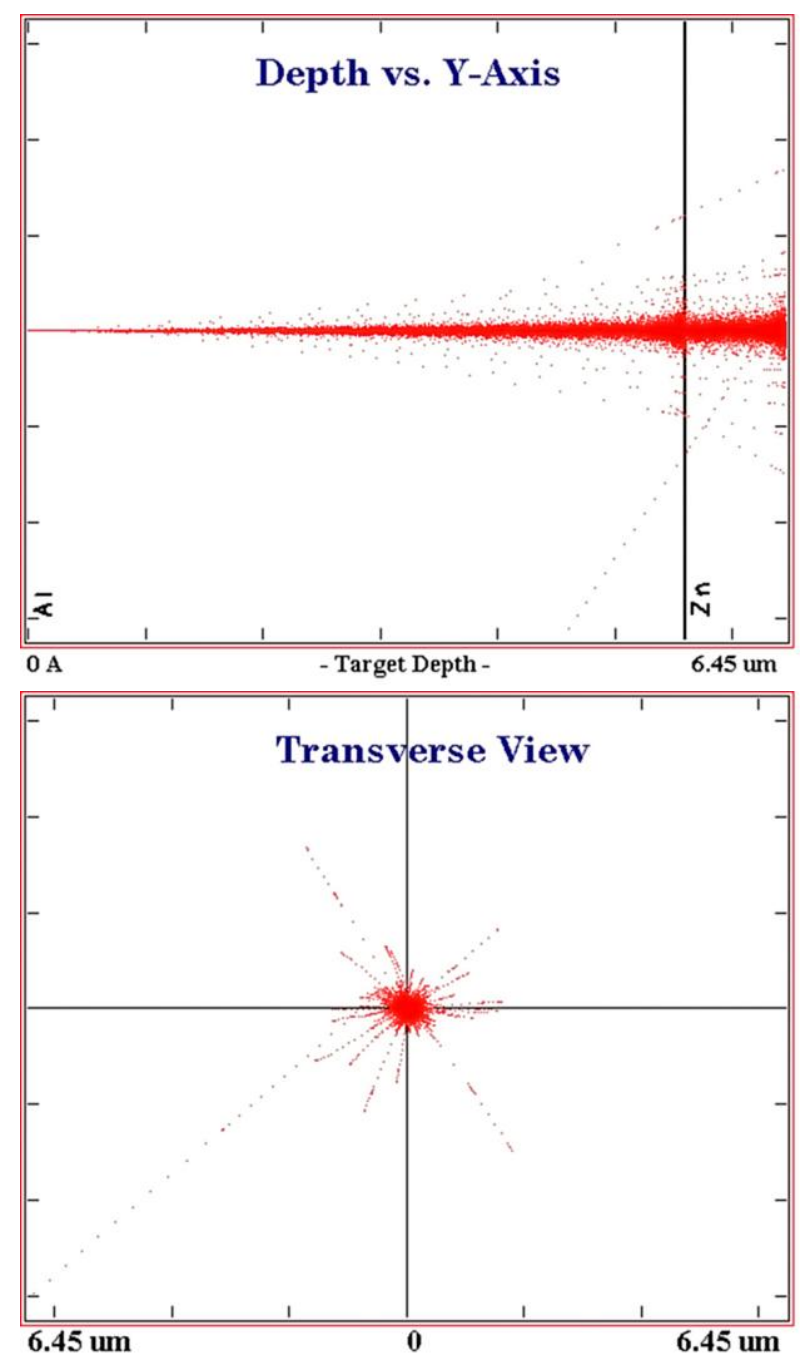

Fig. 2. Ion trajectories in Al-Zn target for normal incidence
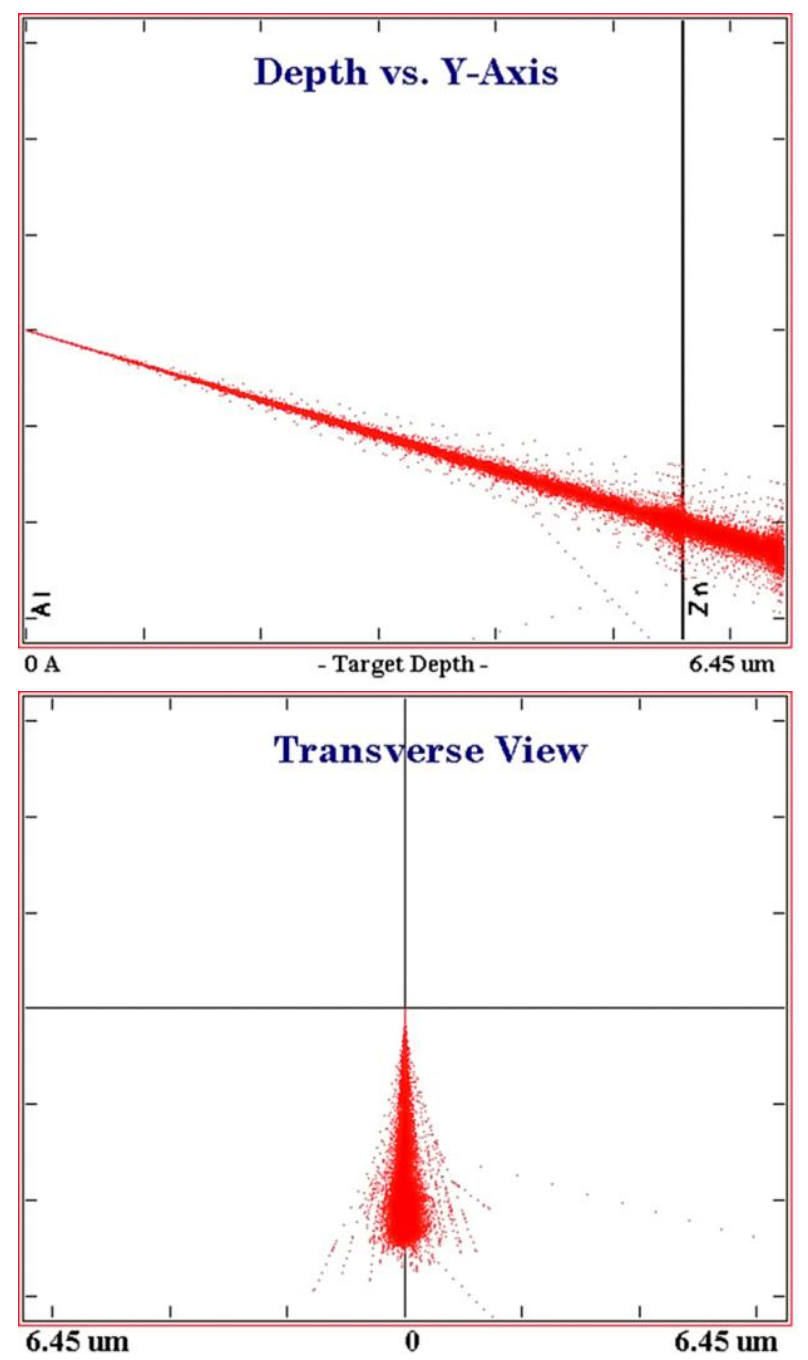

Fig. 3. Ion trajectories in Al-Zn target for oblique incidence at angle of $20^{\circ}$

\section{RESULTS AND DISCUSSIONS}

The measurements showed that for zinc forward emission was higher than backward ones, and $\mathrm{R}$ ratio was equal 1.83 , that is in good agreement with previous results for other materials $[8,12,13,15]$.

As we mentioned above it is considered theoretically and experimentally confirmed that electron yield of ioninduced emission is directly proportional to the specific energy losses (stopping power) of a fast ion in a substance. This conclusion concerns primarily slow, true secondary electrons. It is logical to assume that the Mekbach's factor also depends on the energy loss of the ion in a substance. We summarized $\mathrm{R}$ data from our previous experiments $[8,12,13,15]$ and from the paper [2]. Fig. 4 shows the dependence of $\mathrm{R}$ ratio on stopping power for various materials, which are given in the series of works $[8,12,13,15]$. In addition, the figure shows data for a thin carbon film bombarded by lithium ions from A. Clouvas's work [2]. As can be clearly seen, the hypothesis of the dependence of the Mekbach factor on stopping power is experimentally confirmed.

As it was found earlier [16], energy distribution function of electron emission induced by fast ions, had power-law dependence. Besides, it was shown experimentally that energy distribution function for 
metals had a piecewise-power-law character (two energy intervals) with various power indices for the energy interval $0 \ldots 30$ and $30 \ldots 100 \mathrm{eV}$. The power index for slow electrons was significantly higher than for more energetic electrons (with energies higher than $30 \mathrm{eV})$.

For slow electrons, the influence of conditions of their output from the surface (taking into account a larger power index) will significantly change the value of total electron yield. Thus, an increase in the work function value leads to a decrease in the electron yield (mainly slow electrons) from the material being studied. This effect occurs both in the case of forward and backward electron emissions. However, forward and backward distribution functions differ significantly in the high-energy part. It is well known that fast electrons (convoy and delta electrons) contribute mainly to forward emission [6]. Consequently, an increase in the work function leads to a relative decrease in the backward electron yield in comparison with forward one.

Fig. 5 demonstrates the dependence of $\mathrm{R}$ ratio on the work function of materials that were used as targets in a series of experiments $[8,12,13,15]$. The values of work function were taken from the handbook [17]. The curve fits well with our assumption about relation between $\mathrm{R}$ and work function.

In addition, it was previously shown that the power index in the first energy interval increased with growth of energy losses of the ion in a substance. This leads to a relative decrease of electron emission from the collector (backward yield) due to a decrease in the number of slow electrons, while there is a small highenergy component (convoy and $\delta$-electrons) in the energy distribution of backward emitted electrons. This tendency of more rapid decrease of backward electron yield in comparison with forward one also affects the Mekbach's ratio. As a result the $\mathrm{R}$ ratio increases with growth of the stopping power (see Fig. 4).

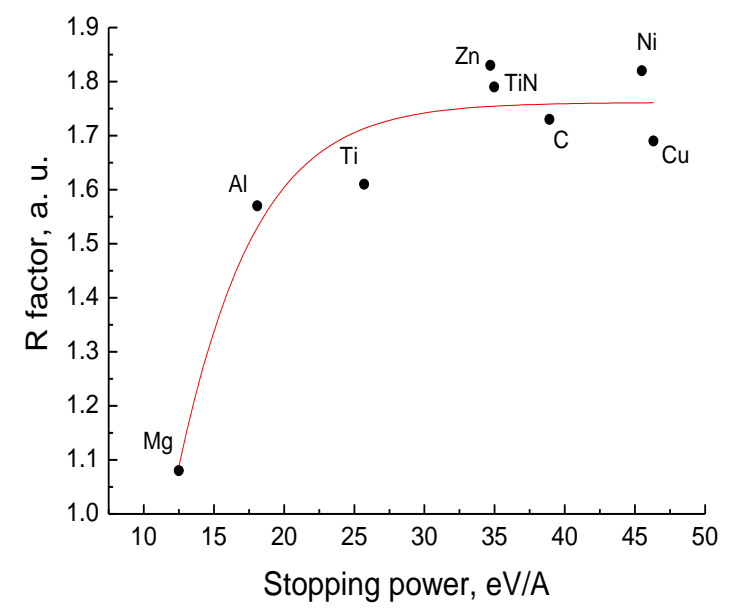

Fig. 4. $R$ ratio as a function of stopping power for different materials (approximating solid line curve is shown to guide eye)

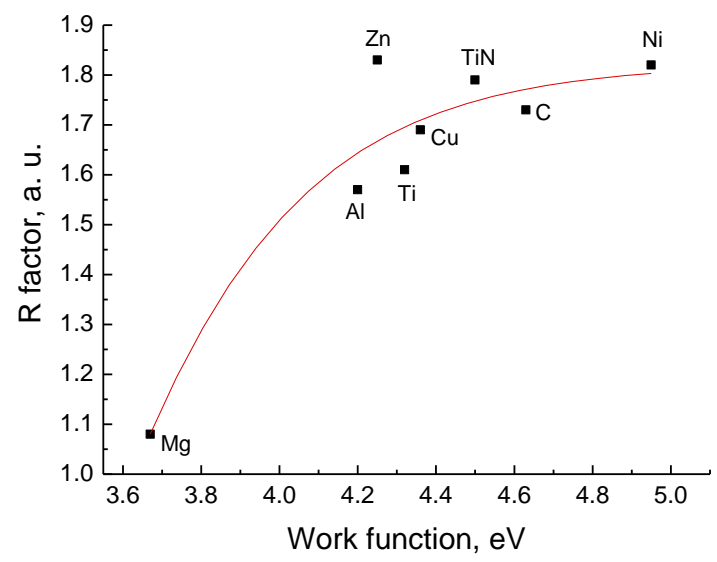

Fig. 5. $R$ ratio dependence on work function for different materials (approximating solid line curve is shown to guide eye)

\section{CONCLUSIONS}

The paper presents the experimental results of zinc electron emission induced by the flux of $\alpha$-particles emitted by radioisotope source. The electron yields for forward and backward emission were measured for the same energy of $\alpha$-particles. The last fundamentally distinguished our experiment from other studies, in which the corresponding electron yields were measured from both surfaces of a thin, most often, carbon foil during the passage of a beam of fast ions. Zinc Mekbach's ratio calculated basing on forward-backward measurements was in good agreement with the data obtained in our previous works for several metals and the data published by A. Clouvas's group for the carbon foil target and lithium ions [2].

We demonstrated that the Mekbach's ratio for various substances depended on the stopping power of a fast ion. The reasons have been discussed in the paper.

In addition, it was shown that work function of a substance significantly affected the ratio of the forward and backward electronic yields. This fact was associated with piecewise power-law energy distribution function of emission electrons and significantly higher power index on the first energy interval in comparison with one for more energetic electrons.

\section{ACKNOWLEDGEMENT}

We would like thank to D. L. Ryabchikov for assistance in sample preparing and $\mathrm{Zn}$ layer deposition.

\section{REFERENCES}

1. W. Meckbach, G. Braunstein, N. Arista. Secondaryelectron emission in the backward and forward directions from thin carbon foils traversed by 25...250 keV proton beams // J. Phys. B. 1975, v. 8, № 14, p. L344-L349.

2. A. Clouvas et al. Role of projectile electrons in secondary electron emission from solid surfaces under fast-ion bombardment // Phys. Rev. B. 1997, v. 55, p. $12086-12098$. 
3. H. Rothard et al. Secondary-electron yields from thin foils: A possible probe for the electronic stopping power of heavy ions // Phys. Rev. A. 1990, v. 41, p. 2521-2536. 4. H. Rothard. Electron ejection from solids by heavy ions at high energies $(1 \ldots 100 \mathrm{MeV} / \mathrm{u}) / / \mathrm{Nucl}$. Instr. and Meth. B. 1998, v. 146, p. 1-10.

5. H. Rothard, J. Schou, K.O. Groeneveld. Projectileand charge-state-dependent electron yields from ion penetration of solids as a probe of preequilibrium stopping power // Phys. Rev. A. 1992, v. 45, p. 17011710.

6. H. Rothard et al. Strong projectile-dependent forward-backward asymmetry of electron ejection by swift heavy ions in solids // Phys. Rev. A. 1998, v. 57, p. 3660-3664.

7. T. Kaneko, Y. Mitsunobu. Forward/backward secondary electron emission from foils by swift ion impact // Nucl. Instr. and Meth. B. 1994, v. 90, p. 560563.

8. V.P. Zhurenko, S.I. Kononenko, V.I. Karas', V.I. Muratov. Dissipation of the Energy of a Fast Charged Particle in a Solid-State Plasma // Plasma Physics Reports. 2003, v. 29, № 2, p. 130-136.

9. E.J. Sternglass. Theory of secondary electron emission by high-speed ions // Phys. Rev. 1957, v. 108, № 1, p. 1-12.

10. J. Schou. Transport theory for kinetic emission of secondary electrons from solids // Phys. Rev. B. 1980, v. 22, p. 2141-2173.
11. D. Hasselkamp et al. Particle Induced Electron Emission II // Springer Tracts in Modern Physics. 2006, v. 123.

12. V. Zhurenko et al. $\alpha$-particle induced forwardbackward electron emission from titanium nitride // Problems of Atomic Science and Technology. Series «Plasma Physics» (116). 2018, № 4 p. 293-296.

13. V. Zhurenko et al. Secondary electron emission induced by $\alpha$-particles from $\mathrm{Mg}-\mathrm{MgO}$ layers // Problems of Atomic Science and Technology. Series «Plasma Physics» (122). 2019, № 4, p. 207-210.

14. J.F. Ziegler, J.P. Biersack, U. Littmark. SRIM - The stopping and range of ions in matter // Nucl. Instrum. Methods Phys. Res. B. 2010, v. 268, p. 1818-1823. http://dx. doi.org/10.1016/j.nimb.2010.02.091

15. S.I. Kononenko, V.P. Zhurenko, O.V. Kalantaryan, A.A. Semerenskiy. Forward and backward electron emission in binary cell of radioisotope current source // Problems of Atomic Science and Technology. Series «Plasma Physics» (9). 2015, № 4, p. 331-334.

16. S.I. Kononenko et al. energy distributions of electrons in stainless steel bombarded by fast ions // Journal of Kharkiv University. 2004, v. 619, p. 119-122. 17. H.B. Michaelson. The work function of the elements and its periodicity // J. Appl. Phys. 1977, v. 48, p. 4729. doi: $10.1063 / 1.323539$.

Article received 10.10.2020

\section{ОТНОШЕНИЕ КОЭФФИЦИЕНТОВ ВЫХОДА ЭЛЕКТРОНОВ НА ПРОСТРЕЛ И НА ОТРАЖЕНИЕ ДЛЯ ИНДУЦИРОВАННОЙ $\alpha$-ЧАСТИЦАМИ ЭМИССИИ ИЗ РАЗЛИЧНЫХ МАТЕРИАЛОВ}

\section{В.П. Журенко, С.И. Кононенко, О.В. Калантарьян, С.С. Авотин, Н.Я. Рохманов}

Измерено отношение коэффициентов эмиссии электронов на прострел и на отражение, которая индуцирована изотропным потоком $\alpha$-частиц из цинка. На основе измеренных значений и экспериментальных данных, полученных в более ранних экспериментах для других материалов, проведена систематизация отношения коэффициентов на прострел и отражение, и установлена связь этого параметра с удельными ионизационными потерями иона в веществе. Проанализирована зависимость работы выхода электронов для различных материалов от отношения коэффициентов эмиссии.

\section{ВІДНОШЕННЯ КОЕФЦЦЕНТІВ ВИХОДУ ЕЛЕКТРОНІВ НА ПРОСТРІЛ І НА ВІДБИТТЯ ДЛЯ ІНДУКОВАНОЇ $\alpha$-ЧАСТИНКАМИ ЕМІСІЇ 3 РІЗНИХ МАТЕРІАЛІВ}

В.П. Журенко, С.І. Кононенко, О.В. Калантар'ян, С.С. Авотін, М.Я. Рохманов

Виміряно відношення коефіцієнтів емісії електронів на простріл і на відбиття, яка індукована ізотропним потоком $\alpha$-частинок 3 цинку. На основі виміряних значень і експериментальних даних, отриманих в попередніх експериментах для інших матеріалів, проведена систематизація відношення коефіцієнтів на простріл і відбиття, і встановлено зв'язок цього параметра з питомими іонізаційними втратами іона в речовині. Проаналізовано залежність роботи виходу електронів для різних матеріалів від відношення коефіцієнтів емісії. 